\title{
Using Modified RECIST and Alpha-Fetoprotein Levels to Assess Treatment Benefit in Hepatocellular Carcinoma
}

\author{
Jean-Luc Raoula Joong-Won Park ${ }^{\mathrm{b}}$ Yoon-Koo Kang ${ }^{\mathrm{c}}$ \\ Richard S Finn ${ }^{d}$ Jun Suk Kim ${ }^{e}$ Winnie Yeo ${ }^{f}$ Blasé N Politeg \\ ${\text { Yee } \text { Chao }^{\text {h }} \text { Ian Walters }}^{i}$ Christine Baudelet ${ }^{j}$ Riccardo Lencionik

\begin{abstract}
${ }^{a}$ Département d'Oncologie Médicale, Institut Paoli-Calmettes, Marseille, France, ${ }^{b}$ National Cancer Center, Goyang, 'Asan Medical Center, Seoul, Republic of Korea, dGeffen School of Medicine, UCLA, Los Angeles, Calif., USA, eKorea University Guro Hospital, Seoul, Republic of Korea, ${ }^{\mathrm{T}}$ The Chinese University of Hong Kong, Shatin, Hong Kong, SAR, China, 9The University of Chicago Medical Center, Chicago, Ill., USA, hVeterans General Hospital, Taiwan, Republic of China, 'Bristol-Myers Squibb, Princeton, N.J., USA, jBristol-Myers Squibb, Braine l'Alleud, Belgium, kPisa University Hospital, Pisa, Italy
\end{abstract}

\section{Key Words}

Alpha-fetoprotein $\cdot$ Brivanib $\cdot$ Hepatocellular carcinoma $\cdot$ mRECIST $\cdot$ WHO criteria

\begin{abstract}
Background and Aims: Assessing treatment responses in hepatocellular carcinoma (HCC) is challenging, and alternative radiologic methods of measuring treatment response are required. Modified Response Evaluation Criteria in Solid Tumors (mRECIST) for HCC and alphafetoprotein (AFP) levels were assessed in a post hoc analysis of a phase II study of brivanib, a selective dual inhibitor of fibroblast growth factor and vascular endothelial growth factor signaling. Methods: HCC patients were treated with first-line (cohort $A ; n=55$ ) or second-line (cohort $B ; n=46$ ) brivanib alaninate 800 mg once daily. Outcomes were compared between World Health Organization (WHO) criteria and (retrospectively by) mRECIST by independent review. The relationship between on-study AFP changes and outcome was analyzed in patients with elevated AFP at baseline. Results: Response rates were higher with mRECIST versus WHO criteria in cohorts A ( $25.5 \%$ vs. $7.3 \%)$ and B ( $10.9 \%$ vs. $4.3 \%)$. Progressive disease (PD) as assessed by mRECIST was associated with a very short median overall survival (OS; cohort A, 2.8 months; cohort B, 5.3 months); PD as assessed by WHO criteria reflected a
\end{abstract}

Jean-Luc Raoul, MD, PhD

Department of Medical Oncology, Paoli-Calmettes Institute FR-13273 Marseille (France)

Tel. +334 9122 3679, E-mail raoulj|@ipc.unicancer.fr 
mixed population of patients with better outcomes. mRECIST responders tended to have a $>50 \%$ AFP decrease during therapy. In cohorts A and B pooled, an early AFP response $(>20 \%$ or $>50 \%$ decline from baseline within the first 4 weeks) was not associated with longer median OS. Conclusions: Tumor response as assessed by mRECIST differed from that by WHO criteria, with mRECIST possibly identifying true nonresponders with a poor prognosis. Many patients had AFP decreases correlating with tumor shrinkage, yet an association with longterm benefit was unclear. mRECIST and on-treatment AFP levels are being explored further with brivanib in HCC.

Copyright $(2014$ S. Karger AG, Basel

\section{Introduction}

The development of new agents to treat hepatocellular carcinoma (HCC) is challenging. Sorafenib, an oral multitarget tyrosine kinase inhibitor, was the first agent to improve OS in patients with advanced HCC, yet the response rate was only 2\% [1]. Studies of HCC have historically assessed treatment response using objective radiologic measurements of tumor size as defined by World Health Organization (WHO) criteria (Table 1) [2] or the Response Evaluation Criteria in Solid Tumors (RECIST) (Table 1) [3]. However, the liver is unique in its fibrous architecture, and even when lesions are mechanically ablated, the remaining cavity retains the appearance of a lesion on imaging [4]. It takes time for the liver to regenerate and fill the cavity, and, hence, show a reduction in lesion diameter on imaging. Therefore, these radiologic assessment methods in HCC have several limitations (no pathologic correlation with tumor measurement, need for uniform image acquisition parameters, reproducibility questionable, measurement sometimes challenging) $[3,5]$, and determining whether a pa-

Table 1. Response criteria for hepatocellular carcinoma target lesions

\begin{tabular}{|c|c|c|}
\hline $\begin{array}{l}\text { Response } \\
\text { category }\end{array}$ & WHO & mRECIST \\
\hline $\begin{array}{l}\text { Complete } \\
\text { response (CR) }\end{array}$ & Disappearance of all known disease & $\begin{array}{l}\text { Disappearance of any intratumoral } \\
\text { arterial enhancement in typical intra- } \\
\text { hepatic lesions and disappearance of } \\
\text { all other target lesions }\end{array}$ \\
\hline $\begin{array}{l}\text { Partial } \\
\text { response (PR) }\end{array}$ & $\begin{array}{l}\geq 50 \% \text { decrease in the sum of the product } \\
\text { of the two longest perpendicular diam- } \\
\text { eters of target lesions } \\
\text { (reference: baseline sum) }\end{array}$ & $\begin{array}{l}\geq 30 \% \text { decrease in the sum of diam- } \\
\text { eters of target lesions (two lesions per } \\
\text { organ, maximum of five lesions) } \\
\text { (reference: baseline sum) }\end{array}$ \\
\hline $\begin{array}{l}\text { Stable disease } \\
\text { (SD) }\end{array}$ & Does not qualify for either PR or PD & Does not qualify for either PR or PD \\
\hline $\begin{array}{l}\text { Progressive } \\
\text { disease (PD) }\end{array}$ & $\begin{array}{l}\geq 25 \% \text { increase in the sum of the product } \\
\text { of two longest perpendicular diameters } \\
\text { (reference: smallest sum recorded since } \\
\text { treatment started) }\end{array}$ & $\begin{array}{l}\geq 20 \% \text { increase in the sum of diameters } \\
\text { of target lesions. (two lesions per } \\
\text { organ, maximum of five lesions) } \\
\text { (reference: smallest sum recorded } \\
\text { since treatment started) }\end{array}$ \\
\hline
\end{tabular}

Adapted with permission from Therasse P, et al. J Natl Cancer Inst 2000;92:205-216 and Lencioni R, et al. Semin Liver Dis 2010;30:52-60 [3]. 
tient is benefiting from therapy is difficult, particularly when assessing targeted therapies. In addition, HCC often occurs in the setting of chronic liver disease with regenerative nodules that may resemble new lesions on imaging [3]. For these reasons, the American Association for the Study of Liver Diseases - Journal of the National Cancer Institute (AASLD-JNCI) guidelines proposed amendments to RECIST, known as modified RECIST (mRECIST, Table 1), for HCC [5]. How these guidelines should be applied in practice was not specified, so we developed procedures for trial implementation and retrospectively reviewed our phase II study population using these principles.

Given the challenges of radiologic treatment assessment in HCC, alternative methods of measuring treatment response are being investigated, including monitoring alpha-fetoprotein (AFP) levels during treatment (on-treatment AFP levels) [6-10]. AFP is a glycoprotein that is normally expressed by fetal tissues, but it is aberrantly secreted into the serum of approximately $70 \%$ of patients with HCC $[7,8]$. While several studies suggest an association between on-treatment AFP levels and benefits from systemic or locoregional therapies for HCC [6-9], there is no consensus on how to define an AFP response, and on-treatment AFP levels have not been established as a surrogate marker for disease evolution under treatment.

Brivanib, a selective dual inhibitor of fibroblast growth factor (FGF) and vascular endothelial growth factor (VEGF) signaling, has demonstrated potent antitumor and antiangiogenic effects in preclinical models of various tumor types, including HCC [11-14]. Results from a phase II study with brivanib demonstrated promising clinical activity in patients with unresectable, locally advanced, or metastatic HCC $[15,16]$; unfortunately, randomized controlled trials of brivanib as first-line and second-line therapy have failed $[17,18]$. Here we report the results of exploratory post hoc analyses from the above-mentioned phase II study that assess the ability of mRECIST for HCC and on-treatment AFP levels to predict clinical outcomes. This study is one of the first to report an analysis using mRECIST for HCC by independent review. Overall efficacy and safety results from this study were reported elsewhere $[15,16]$.

\section{Patients and Methods}

\section{Study Design}

A description of the study design was published previously $[15,16]$. In summary, it was a multicenter, open-label, phase II, single-agent study of brivanib alaninate in patients with unresectable, locally advanced, or metastatic HCC. Patients had either received no prior systemic therapy (cohort A) or had progressed following one prior antiangiogenic therapy regimen including sorafenib, sunitinib, thalidomide, or bevacizumab (cohort B). Brivanib alaninate was administered orally at a dose of $800 \mathrm{mg}$ daily and was given continuously until disease progression or unacceptable toxicity. Tumor response was assessed using WHO criteria by an Independent Response Review Committee (IRRC).

The primary end point was 6-month progression-free survival (PFS) rate in cohort A. Secondary end points in cohort $A$ and primary end points in cohort B included tumor response rate, time to response, duration of response, PFS, OS, disease control rate (DCR), and safety and tolerability. The tumor response rate was the proportion of patients with a complete response (CR) or partial response (PR). DCR was the proportion of treated patients whose best response was CR, PR, or stable disease (SD) lasting $\geq 42$ days.

Tumor Response Assessment

In the initial analysis, tumor response was assessed every 6 weeks using WHO criteria via computed tomography (CT) or magnetic resonance imaging (MRI). This phase II brivanib study was designed in April 2006 prior to the recent AASLD-JNCI guidelines for HCC, which recommend tumor response assessment by mRECIST for HCC [3]. In the current post hoc analysis, all scans were retrospectively reassessed using WHO and mRECIST (maximum of two lesions per organ and five in total) for HCC by an independent radiologist (RL) who was blinded to previous imaging and outcome results and was not involved in the initial reads. To evaluate the validity of mRECIST for HCC in predicting clinical outcomes, the tumor responses (CR, PR, SD, or PD), DCR, and median time to progression (TTP) determined by mRECIST for HCC 
were compared with those determined by WHO criteria for cohorts A and B separately. Median OS was compared between patients with and without disease control, as determined by WHO criteria and mRECIST for HCC. For the OS analyses, hazard ratios (HRs) and 95\% confidence intervals (CIs) were provided. In addition, landmark OS analyses [19] at 3, 6, and 9 months were performed to assess consistency of the predictive effect.

AFP Response Assessment

Among patients with elevated baseline AFP ( $\geq 20 \mathrm{ng} / \mathrm{ml})$, on-study levels were determined at the first dose; at weeks 1, 2, 3, and 6; every 3 weeks from week 9; every 6 weeks from week 12; and at the end of treatment. An early AFP response was determined for patients with a baseline AFP $\geq 20 \mathrm{ng} / \mathrm{ml}$ and at least one on-study AFP level and was defined as a $>20 \%$ decrease from baseline within 4 weeks of the start of treatment (best decrease) $[6,8]$. Changes in on-study AFP levels over time were plotted for groups of early AFP responders and patients without an early response (i.e., late responders or those with AFP that increased over time) pooled from cohorts A and B. Additionally, the proportion of patients with at least a 50\% decrease from baseline in AFP was determined among mRECIST for HCC responders in cohorts A and B separately who had baseline AFP levels greater than the upper limit of normal (approximately $10 \mathrm{ng} / \mathrm{ml}$ [range: 8-24 ng/ml]) and at least one on-study AFP assessment. Furthermore, the associations between early AFP response by four definitions ( $>20 \%$ or $>50 \%$ decrease after 4 weeks of treatment from baseline and AFP $>20 \mathrm{ng} / \mathrm{ml}$ or $>200 \mathrm{ng} / \mathrm{ml}$ ) and OS were assessed in pooled patients from cohorts A and B. In this analysis, HRs and 95\% CIs were computed from Cox Proportional Hazard model regression.

\section{Results}

\section{Patients}

Patient characteristics for cohorts A $(n=55)$ and B $(n=46)$ were described previously $[15,16]$. Risk factors for HCC were consistent with the geographical distribution of patients. Since many of the patients came from Asia, the predominant risk factor was hepatitis B virus (56.9\%), followed by hepatitis $C$ virus $(22.0 \%)$ and alcoholic liver disease $(20.3 \%)$. Concomitant antiviral therapies were used in 13 patients (23.6\%) in cohort A and 22 patients $(47.8 \%)$ in cohort B. Most patients had extrahepatic disease (respectively $76 \%$ and $78 \%$ in cohorts A and B) and Barcelona Clinic Liver Cancer stage C (respectively $89 \%$ and $96 \%$ in cohorts A and B). In cohort B, the most commonly used prior systemic therapy was sorafenib (94\%) [16].

\section{Reassessment of Response by mRECIST for HCC}

Reanalysis of MRI/CT scans for HCC was performed in a total of 101 patients who had on-study scans. In cohort A, the confirmed tumor response rate (CR + PR) increased from $7.3 \%$ with WHO criteria to $25.5 \%$ with mRECIST, and DCR increased from $50.9 \%$ to $78.2 \%$ (Table 2). It should be noted that there may have been more responders, because some patients who discontinued treatment as a result of PD assessed by WHO criteria may later have been classified as responders using mRECIST had they stayed on study. Applying mRECIST in cohort A upgraded the response in 26 patients and downgraded the response in 2 patients. Scans for one patient in cohort A who converted to CR from PR are shown in fig. 1. In cohort $\mathrm{B}$, tumor response rate increased from $4.3 \%$ with WHO criteria to $10.9 \%$ with mRECIST, and DCR increased from $43.5 \%$ to $71.7 \%$ (Table 2). Applying mRECIST in cohort B upgraded the response in 17 patients and downgraded the response in 2 patients (Table 3). Median TTP also appeared to improve when assessed by mRECIST, increasing from 2.8 months to 5.4 months in cohort A, and from 1.4 months to 6.9 months in cohort B (Table 2). However, because patients originally assessed with PD by WHO criteria were taken off treatment and had no further scans, the TTP analysis for mRECIST suffered much more from censored data, which could have affected the estimation of TTP. 


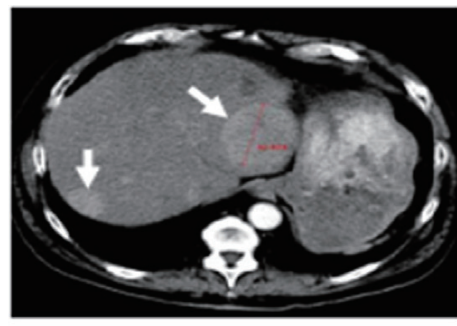

04 Jun 07 Baseline assessment

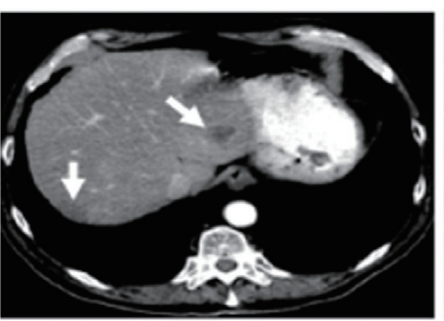

12 Dec 07

WHO: PR

mRECIST: CR

Fig. 1. Example of a patient treated with first-line brivanib alaninate $800 \mathrm{mg}$ once daily (cohort A) who was initially assessed as having PR by WHO criteria. On scan reassessment by mRECIST, this patient was classified as having CR. Adapted with permission from Park JW, Finn RS, Kim JS, et al. Phase II, open-label study of brivanib as first-line therapy in patients with advanced hepatocellular carcinoma. As described by Park JW, et al. [15].

Table 2. Tumor response and TTP using WHO criteria and mRECIST

\begin{tabular}{|c|c|c|c|c|}
\hline & \multicolumn{2}{|l|}{$\begin{array}{l}\text { Cohort A } \\
(n=55)\end{array}$} & \multicolumn{2}{|l|}{$\begin{array}{l}\text { Cohort B } \\
(n=46)\end{array}$} \\
\hline & $\mathrm{WHO}^{\mathrm{a}}$ & mRECIST & $\mathrm{WHO}^{\mathrm{a}}$ & mRECIST \\
\hline $\begin{array}{l}\text { Best tumor response, } \mathrm{n}(\%) \\
\text { CR } \\
\text { PR } \\
\text { SD }\end{array}$ & $\begin{array}{l}1(1.8) \\
3(5.5) \\
24(43.6)\end{array}$ & $\begin{array}{l}5(9.1) \\
9(16.4) \\
29(52.7)\end{array}$ & $\begin{array}{l}0 \\
2(4.3) \\
18(39.1)\end{array}$ & $\begin{array}{l}0 \\
5(10.9) \\
28(60.9)\end{array}$ \\
\hline Response rate $^{\mathrm{b}}, \%(\mathrm{n} / \mathrm{N})$ & $7.3(4 / 55)$ & $25.5(14 / 55)$ & $4.3(2 / 46)$ & $10.9(5 / 46)$ \\
\hline $\mathrm{DCR}^{\mathrm{c}}, \%(\mathrm{n} / \mathrm{N})$ & $50.9(28 / 55)^{\mathrm{d}}$ & $78.2(43 / 55)^{\mathrm{e}}$ & $43.5(20 / 46)$ & $71.7(33 / 46)^{f}$ \\
\hline $\begin{array}{l}\text { Number progressed/ } \\
\text { number treated patients }\end{array}$ & $34 / 55$ & $18 / 55$ & $30 / 46$ & $14 / 46$ \\
\hline $\begin{array}{l}\text { Median TTP (months) } \\
(95 \% \mathrm{CI})\end{array}$ & $\begin{array}{l}2.8 \\
(1.4-3.5)\end{array}$ & $\begin{array}{l}5.4 \\
(2.8-\mathrm{NR})\end{array}$ & $\begin{array}{l}1.4 \\
(1.4-2.7)\end{array}$ & $\begin{array}{l}6.9 \\
(3.9-N R)\end{array}$ \\
\hline
\end{tabular}

Cohort A: brivanib alaninate $800 \mathrm{mg}$ once daily and no prior systemic therapy; Cohort B: brivanib

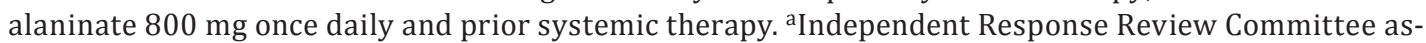
sessment. ${ }^{\mathrm{b}}$ Response rate $=\mathrm{CR}+\mathrm{PR}$. ${ }^{\mathrm{C}}$ Disease control rate $=\mathrm{CR}+\mathrm{PR}+\mathrm{uCR}+\mathrm{uPR}+\mathrm{SD} .{ }^{\mathrm{d}} \mathrm{DCR}$ includes 2 uPRs. ${ }^{\text {DCR }}$ includes 2 uCRs and 3 uPRs. ${ }^{\mathrm{f}} \mathrm{DCR}$ includes $1 \mathrm{uPR}$. uCR=unconfirmed complete response; $\mathrm{uPR}=$ unconfirmed partial response; $\mathrm{NR}=$ not reached.

As previously reported, median OS was 10.0 months (95\% CI, 6.8-15.2 months) in cohort A and 9.8 months (95\% CI, 5.5-13.2 months) in cohort B. In cohort A, the HR:OS ratio for disease control (CR + PR + SD) over no disease control (PD) decreased from 0.56 with WHO to 0.31 with mRECIST criteria, and patients with PD by mRECIST had a very poor outcome compared with patients with PD by WHO criteria (median OS, 2.8 months vs. 5.1 months, respectively) (fig. 2A). There was better separation of the two survival curves (disease control vs. no disease control) with mRECIST compared with WHO. These results were consistent with the landmark analysis at month 3 in cohort A (fig. 2B), as well as landmark analyses done 
Table 3. Shift in best tumor response using WHO criteria and mRECIST in cohorts A and B

\begin{tabular}{|c|c|c|c|c|c|c|}
\hline \multicolumn{7}{|l|}{ Cohort A } \\
\hline \multirow{2}{*}{$\begin{array}{l}\text { mRECIST best } \\
\text { response }\end{array}$} & \multicolumn{6}{|c|}{ WHO best response $\mathrm{e}^{\mathrm{a}}$} \\
\hline & $\mathrm{CR}$ & PR & SD & PD & UTD & Total \\
\hline CR & 1 & 1 & 3 & 0 & 0 & 5 \\
\hline PR & 0 & 1 & 6 & 2 & 0 & 9 \\
\hline SD & 0 & 1 & 14 & 14 & 0 & 29 \\
\hline PD & 0 & 0 & 1 & 4 & 0 & 5 \\
\hline UTD & 0 & 0 & 0 & 0 & 7 & 7 \\
\hline Total & 1 & 3 & 24 & 20 & 7 & 55 \\
\hline \multicolumn{7}{|l|}{ Cohort B } \\
\hline \multirow{2}{*}{$\begin{array}{l}\text { mRECIST best } \\
\text { response }\end{array}$} & \multicolumn{6}{|c|}{ WHO best response $\mathrm{a}^{\mathrm{a}}$} \\
\hline & $\mathrm{CR}$ & PR & $\mathrm{SD}$ & PD & UTD & Total \\
\hline $\mathrm{CR}$ & 0 & 0 & 0 & 0 & 0 & 0 \\
\hline PR & 0 & 2 & 2 & 1 & 0 & 5 \\
\hline SD & 0 & 0 & 14 & 14 & 0 & 28 \\
\hline $\mathrm{PD}$ & 0 & 0 & 2 & 5 & 0 & 7 \\
\hline UTD & 0 & 0 & 0 & 0 & 6 & 6 \\
\hline Total & 0 & 2 & 18 & 20 & 6 & 46 \\
\hline
\end{tabular}

Cohort A: brivanib alaninate $800 \mathrm{mg}$ once daily and no prior systemic therapy; cohort B: brivanib alaninate $800 \mathrm{mg}$ once daily and prior systemic therapy. ${ }^{\mathrm{a}}$ Independent Response Review Committee assessment. UTD=unable to determine.

at several other time points (data not shown). These results were less obvious in cohort B with only a trend in identifying a truly poor prognostic group (in patients with PD, median OS was 9.5 months by WHO vs. 5.3 months by mRECIST), but the OS curves for disease control versus no disease control do not appear better separated using mRECIST (HRs, 0.51 with WHO vs. 0.70 with mRECIST) (fig. 3A, 3B). The small numbers of patients in the no disease control group $(n=13)$ using mRECIST limits the power of this analysis and the conclusions regarding second line patients.

\section{On-Treatment AFP Response}

A total of 70 patients (of 101 patients) from pooled cohorts A and B had elevated AFP $(\geq 20 \mathrm{ng} / \mathrm{ml}$ ) at baseline and at least one on-study AFP assessment. Among these patients, an early AFP response ( $>20 \%$ decline from baseline within the first 4 weeks) occurred in $74.3 \%$ $(52 / 70)$ of patients. In this early AFP responders group, dramatic and sustained decreases in AFP levels were evident in some patients. In the non-early AFP responders group ( $\mathrm{n}=$ 

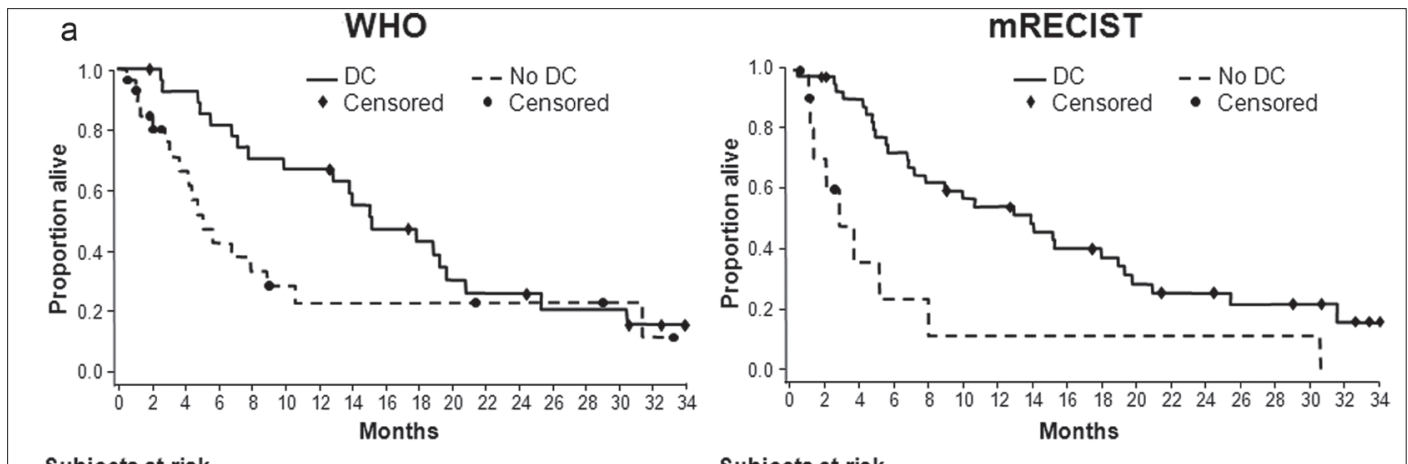

DC $\quad \begin{array}{lllllllllllllllllllllllllllllllllllllll}28 & 27 & 25 & 22 & 19 & 18 & 18 & 15 & 12 & 10 & 7 & 6 & 6 & 4 & 4 & 4 & 2 & 0 & \mathrm{DC} & 43 & 40 & 36 & 29 & 25 & 22 & 21 & 18 & 15 & 13 & 10 & 8 & 8 & 6 & 6 & 5 & 3 & 0\end{array}$ No DC $27 \begin{array}{llllllllllllllllllllllllllllllllllllllllll} & 20 & 14 & 9 & 7 & 5 & 4 & 4 & 4 & 4 & 4 & 3 & 3 & 3 & 3 & 2 & 1 & 0 & \text { No DC } 12 & 7 & 3 & 2 & 1 & 1 & 1 & 1 & 1 & 1 & 1 & 1 & 1 & 1 & 1 & 1 & 0 & 0\end{array}$
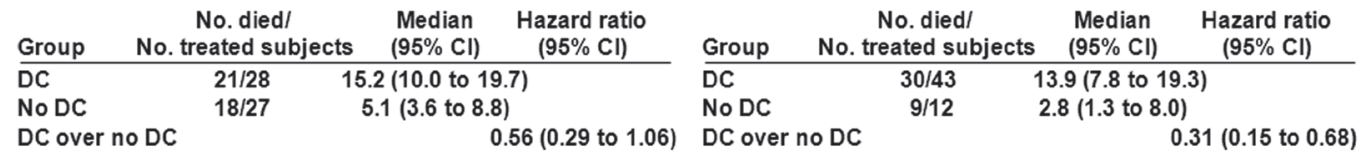

b

WHO

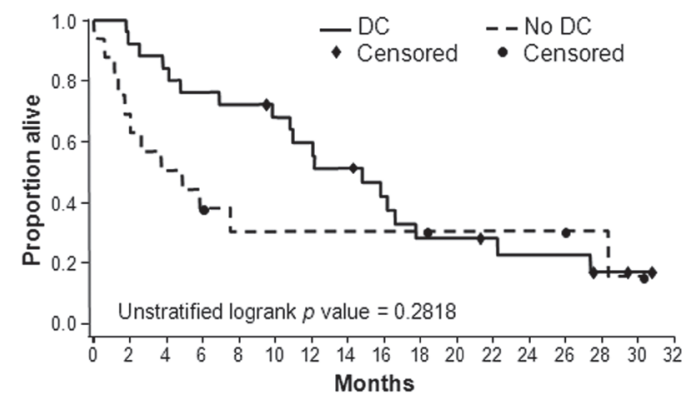

Subjects at risk

Subjects at ris

No. died/ Median Hazard ratio

\begin{tabular}{lccc} 
Group & $\begin{array}{c}\text { No. died/ } \\
\text { No. treated subjects }\end{array}$ & $\begin{array}{c}\text { Median } \\
(95 \% \mathrm{Cl})\end{array}$ & $\begin{array}{c}\text { Hazard ratio } \\
(95 \% \mathrm{Cl})\end{array}$ \\
\hline DC & $19 / 25$ & $14.9(9.9$ to 17.8$)$ \\
No DC & $12 / 16$ & $4.4(1.7$ to 28.4$)$
\end{tabular}

DC over no DC $\quad 0.67(0.32$ to 1.39$)$

\begin{tabular}{lccc} 
Group & No. treated subjects & $\begin{array}{c}\text { Median } \\
(95 \% \mathrm{Cl})\end{array}$ & $\begin{array}{c}\text { Hazard ratio } \\
(95 \% \mathrm{Cl})\end{array}$ \\
\hline DC & $27 / 37$ & $12.1(5.9$ to 16.7$)$ \\
No DC & $4 / 4$ & $3.5(0.6$ to 27.5$)$ \\
DC over no DC & & \multicolumn{2}{c}{$0.52(0.18$ to 1.50$)$}
\end{tabular}

Fig. 2. Overall survival (a) and 3-month landmark overall survival (b) of cohort A according to disease control status.

18), there were some slower AFP responses, and only a few patients showed true non-AFP response (i.e., AFP increases on study).

In cohorts A and B, 41 and 36 patients, respectively, had baseline AFP levels greater than the upper limit of normal (approximately $10 \mathrm{ng} / \mathrm{ml}$ [range, 8-24 ng/ml]) and at least one onstudy AFP assessment (fig. 4). In this patient subgroup, a $50 \%$ or greater decrease in AFP at any time was noted in 56\% (23/41) of patients in cohort A and 56\% (20/36) of patients in cohort B. Responders by mRECIST tended to have at least a 50\% decrease in AFP levels $(8 / 11$ in cohort $A ; 4 / 4$ in cohort B).

Among patients pooled from cohorts A and B, median OS tended to be longer with early AFP response (10.0 -10.8 months) than with no early AFP response (8.0-9.4 months) using four definitions of early AFP response and baseline AFP ( $>20 \%$ or $>50 \%$ decrease from base- 


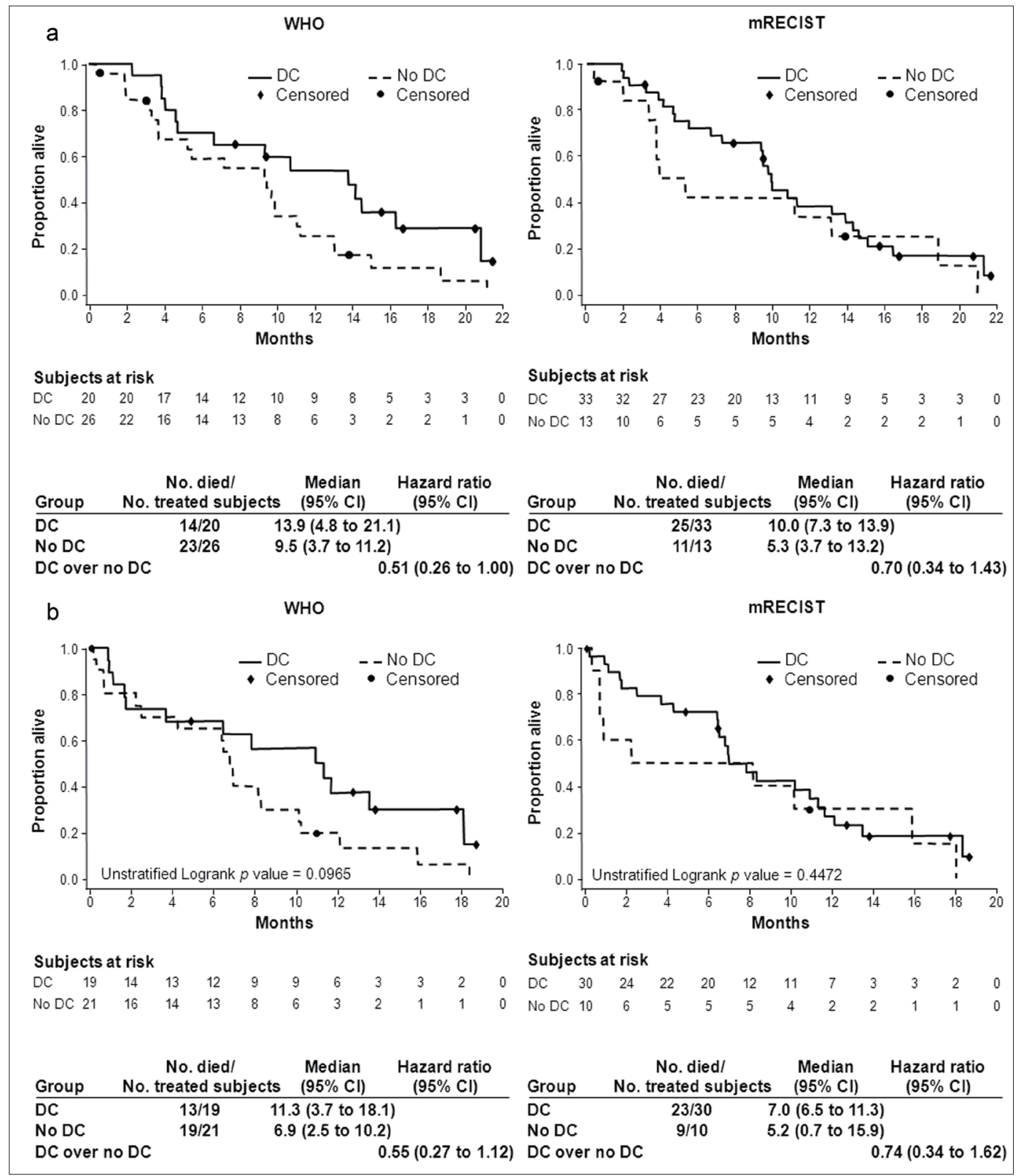

Fig. 3. Overall survival (a) and 3-month landmark overall survival (b) of cohort B according to disease control status.

line after 4 weeks of treatment/>20 ng/ml or $>200 \mathrm{ng} / \mathrm{ml}$ baseline AFP) (Table 4). However, the numbers are small and the study was not powered to detect this magnitude of difference.

\section{Discussion}

Drug development and patient management in HCC are difficult, particularly when tools to measure treatment response are not ideal. The use of mRECIST for HCC was proposed to address the disease-specific aspects of HCC while measuring response to treatment, espe- 


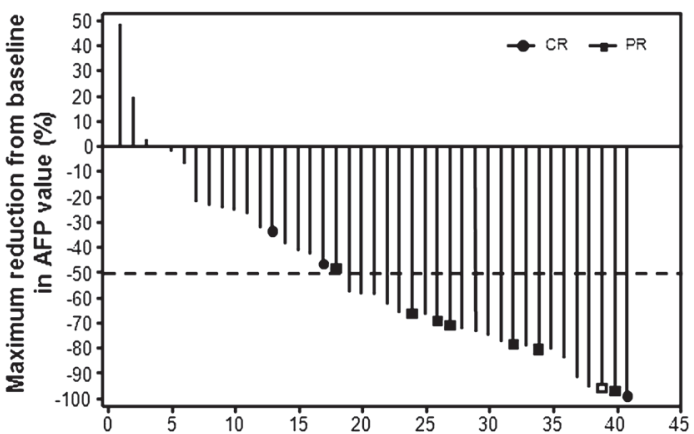

b Prior Systemic Treatment $(n=36)$

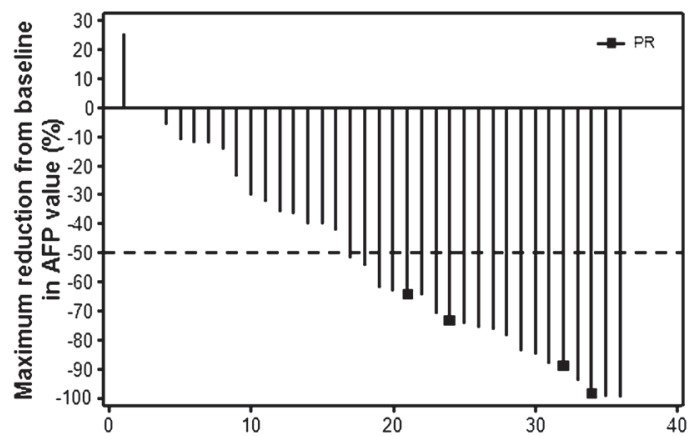

Fig. 4. Best decrease from baseline in AFP level according to mRECIST in treatment-naïve patients (a) and in patients who had received prior therapy (b) Only patients with baseline AFP levels greater than the upper limit of normal (approximately $10 \mathrm{ng} / \mathrm{ml}$ [range: 8-24 ng/ml]) and at least one on-study AFP assessment were included.

Table 4. Survival by early AFP response in patients with elevated AFP at baseline

\begin{tabular}{|c|c|c|c|}
\hline \multirow{2}{*}{$\begin{array}{l}\text { Definition of AFP response/baseline } \\
\text { AFP level }\end{array}$} & \multicolumn{2}{|c|}{$\begin{array}{l}\text { Median OS, months: Analysis of } \\
\text { pooled data from cohorts A and } B^{a}\end{array}$} & \multirow{2}{*}{$\begin{array}{l}\text { Hazard ratio } \\
(95 \% \mathrm{CI})\end{array}$} \\
\hline & $\begin{array}{l}\text { Early AFP } \\
\text { Response }\end{array}$ & $\begin{array}{l}\text { No Early AFP } \\
\text { Response }\end{array}$ & \\
\hline $\begin{array}{l}>20 \% \text { from baseline after } 4 \text { weeks of } \\
\text { treatment }^{\mathrm{a}} />20 \mathrm{ng} / \mathrm{ml}(\mathrm{n}=70)\end{array}$ & 10.0 & 8.0 & $\begin{array}{l}1.19 \\
(0.62-2.29)\end{array}$ \\
\hline $\begin{array}{l}>20 \% \text { from baseline after } 4 \text { weeks of } \\
\text { treatment } />200 \mathrm{ng} / \mathrm{ml}(\mathrm{n}=51)\end{array}$ & 10.8 & 8.0 & $\begin{array}{l}1.08 \\
(0.52-2.24)\end{array}$ \\
\hline $\begin{array}{l}>50 \% \text { from baseline after } 4 \text { weeks of } \\
\text { treatment } />20 \mathrm{ng} / \mathrm{ml}(\mathrm{n}=70)\end{array}$ & 10.0 & 8.0 & $\begin{array}{l}1.12 \\
(0.64-1.97)\end{array}$ \\
\hline $\begin{array}{l}>50 \% \text { from baseline after } 4 \text { weeks of } \\
\text { treatment } />200 \mathrm{ng} / \mathrm{ml}(\mathrm{n}=51)\end{array}$ & 10.0 & 9.4 & $\begin{array}{l}1.56 \\
(0.79-3.07)\end{array}$ \\
\hline
\end{tabular}

Cohort A: brivanib alaninate $800 \mathrm{mg}$ once daily and no prior systemic therapy; Cohort B: brivanib alaninate $800 \mathrm{mg}$ once daily and prior systemic therapy. ${ }^{\mathrm{a}}$ As described by Shao YY, et al. [8]. ${ }^{b}$ Hazard ratio for survival between patients with or without an early AFP response.

cially with targeted therapy $[3,5]$. Indeed, a recent retrospective analysis of 53 patients with advanced HCC treated with sorafenib at a single institution suggests that mRECIST for HCC may be a better method of assessing efficacy with targeted therapy than conventional RECIST [20]. Our retrospective analysis of a prospective study of efficacy of brivanib suggests that mRECIST deserves consideration for assessing efficacy of antiangiogenic drugs in HCC.

Our study sought to further validate the use of mRECIST for HCC by analyzing data from a phase II study with brivanib $[15,16]$. When scans initially assessed using WHO criteria were independently reassessed using mRECIST for HCC, response rates increased more than threefold for patients with no prior systemic therapy (cohort A) and more than two-fold for patients who had undergone prior systemic therapy (cohort B). Notably, 16 and 15 patients in cohorts A and B (representing 29\% and 33\% of each cohort), respectively, who were assessed 


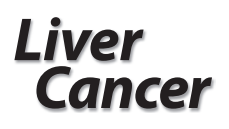

Liver Cancer 2014;3:439-450

DOI: $10.1159 / 000343872$

Publisned onine: August 15, 2014

(c) 2014 S. Karger AG, Basel

Raoul et al.: mRECIST and Hepatocellular Carcinoma

as PD by WHO criteria (and actually taken off treatment) were noted to have experienced some treatment effect by mRECIST for HCC (i.e., SD or PR) and may potentially have benefited from continued treatment. Upgraded responses corresponded in all cases to patients with stable or eventually progressing tumor diameter but with major decrease or disappearance of "viable" tissue on arterial phase scans. In this series, no case was related to new liver nodules considered as PD following WHO criteria but too small or without typical vascular pattern and so not considered for response following mRECIST. By contrast, in cohort A, one case of PR and one case of SD with WHO criteria were reassessed as respectively SD and PD; in both cases the vascularized part of the tumor was increasing in size while tumor diameter remained stable or improved. Furthermore, in cohorts A and B, median TTP increased by approximately 3 months and 6 months, respectively, on reassessment. Therefore, the true treatment effect with brivanib could have been larger if the patients had continued until progression as assessed by mRECIST for HCC.

The real test of new criteria is how well they facilitate treatment decisions. Survival analyses suggest that mRECIST for HCC may better identify a nonresponding population with a poor prognosis that should be considered for alternative therapeutic approaches. Given the uncertainty about using imaging to assess progression, prior trials (e.g., the Sorafenib Hepatocellular Carcinoma Assessment Randomized Protocol [SHARP] trial [1]) mandated that patients continue treatment until both radiologic and clinical progression occurred. In our study, a higher number of patients may have been assessed as having disease progression by the initial WHO criteria (e.g., by detecting new regenerative nodules or ascites). Therefore, it may be possible to better identify patients benefitting from treatment if a revised assessment of progression can be used as a guide, such as in this case mRECIST for HCC [3].

Despite promising results with mRECIST for HCC, the application of these criteria has limitations [3, 21]. For example, the accuracy of mRECIST for HCC could depend on both the quality of the imaging modalities and the ability of the reviewer. Furthermore, mRECIST for HCC is only relevant to hepatic lesions with "typical" HCC features. Therefore, patients with advanced HCC but without lesions in the liver may not have a different assessment by mRECIST for HCC because extrahepatic metastases and atypical intrahepatic lesions are still evaluated by conventional metrics [3]. Moreover, retrospectively applying mRECIST to HCC trials initially conducted with other criteria may introduce major bias [21]. Many patients did not have complete follow-up since their managing physician was guided by WHO criteria for decisions on treatment discontinuation. Therefore, response and TTP were estimated and likely under-represented, so correlations to long-term outcomes are hypothesis generating. Further analyses on prospective trials with these criteria are needed to validate these results.

Because of limitations with radiologic criteria in HCC, on-treatment AFP levels have been investigated as a surrogate marker of therapeutic benefit $[6,10]$. Studies of systemic and locoregional therapies for HCC suggest that decreases in AFP during treatment correlate with improved response and survival [6-9]. However, one study with HCC patients treated with sorafenib showed no significant correlation between on-treatment AFP levels and response [10]. On-treatment AFP levels were investigated in our study as a potential response assessment method for HCC to be used with mRECIST for HCC. In pooled cohorts A and B, approximately $74 \%$ of patients with baseline AFP $\geq 20 \mathrm{ng} / \mathrm{ml}$ demonstrated an early AFP response ( $>20 \%$ decrease within the first 4 weeks) during brivanib therapy, and most mRECIST responders had $\geq 50 \%$ decrease in AFP level. Major reductions in AFP were seen in patients with tumor response as assessed using both criteria. However, using four combinations of definitions of AFP response and baseline AFP in pooled cohorts A and B, an association between early AFP response and longer OS could not be demonstrated (Table 4). Because of the small sample size in this study, the conclusions that can be drawn with AFP are 
limited. It should also be noted that since FGF receptor signaling modulates AFP expression in HCC [22], brivanib treatment could possibly affect the expression of AFP and not affect tumor growth, and so AFP levels may prove to be of limited utility as a reliable surrogate marker of tumor burden. Furthermore, levels of AFP may be affected by viral hepatitis [23]. There are insufficient data from this or other studies to date to indicate that on-treatment AFP level is a reliable HCC biomarker for response, and making treatment decisions based on AFP changes is still considered exploratory.

This post hoc analysis of phase II brivanib data provides insights into response assessment with targeted therapies for unresectable, locally advanced, or metastatic HCC. These results have limitations, including the post hoc nature of the analyses, the small number of patients, and the high degree of censoring, which impede drawing definitive conclusions. However, this study is one of the first to report an analysis using mRECIST for HCC analyzed by an independent, blinded radiologist. In comparison with conventional radiologic response methods, mRECIST for HCC may allow for a better understanding of which patients are likely to experience long-term benefits with targeted therapies for HCC and may avoid unwarranted treatment discontinuation among patients deriving therapeutic benefits. In a recent series focused on HCC patients treated by doxorubicin drug-eluding beads transarterial chemoembolization [24], mRECIST had a better survival correlation than other response evaluation methods. Based on our current study, on-treatment AFP response may reflect the biologic activity of brivanib in individual patients with HCC, but AFP does not appear to perform well as a surrogate prognostic marker.

\section{Acknowledgments}

This research was funded by Bristol-Myers Squibb. Editorial and writing assistance was provided by StemScientific, funded by Bristol-Myers Squibb.

\section{References}

1 Llovet JM, Ricci S, Mazzaferro V, Hilgard P, Gane E, Blanc JF, de Oliveira AC, Santoro A, Raoul JL, Forner A, Schwartz M, Porta C, Zeuzem S, Bolondi L, Greten TF, Galle PR, Seitz JF, Borbath I, Häussinger D, Giannaris T, Shan M, Moscovici M, Voliotis D, Bruix J, SHARP Investigators Study Group: Sorafenib in advanced hepatocellular carcinoma. N Engl J Med 2008;359:378-390.

-2 James K, Eisenhauer E, Christian M, Terenziani M, Vena D, Muldal A, Therasse P: Measuring response in solid tumors: unidimensional versus bidimensional measurement. J Natl Cancer Inst 1999;91:523-528.

-3 Lencioni R, Llovet JM: Modified RECIST (mRECIST) assessment for hepatocellular carcinoma. Semin Liver Dis 2010;30:52-60.

-4 Forner A, Ayuso C, Varela M, Rimola J, Hessheimer AJ, de Lope CR, Reig M, Bianchi L, Llovet JM, Bruix J: Evaluation of tumor response after locoregional therapies in hepatocellular carcinoma: are response evaluation criteria in solid tumors reliable? Cancer 2009;115:616-623.

-5 Llovet JM, Di Bisceglie AM, Bruix J, Kramer BS, Lencioni R, Zhu AX, Sherman M, Schwartz M, Lotze M, Talwalkar J, Gores GJ, Panel of Experts in HCC-Design Clinical Trials: Design and endpoints of clinical trials in hepatocellular carcinoma. J Natl Cancer Inst 2008;100:698-711.

6 Chan SL, Mo FK, Johnson PJ, Hui EP, Ma BB, Ho WM, Lam KC, Chan AT, Mok TS, Yeo W: New utility of an old marker: serial alpha-fetoprotein measurement in predicting radiologic response and survival of patients with hepatocellular carcinoma undergoing systemic chemotherapy. J Clin Oncol 2009;27:446-452.

-7 Vora SR, Zheng H, Stadler ZK, Fuchs CS, Zhu AX: Serum alpha-fetoprotein response as a surrogate for clinical outcome in patients receiving systemic therapy for advanced hepatocellular carcinoma. Oncologist 2009;14:717-725.

8 Shao YY, Lin ZZ, Hsu C, Shen YC, Hsu CH, Cheng AL: Early alpha-fetoprotein response predicts treatment efficacy of antiangiogenic systemic therapy in patients with advanced hepatocellular carcinoma. Cancer 2010;116:4590-4596. 
-9 Kim BK, Ahn SH, Seong JS, Park JY, Kim Y, Kim JK, Lee Y, Lee KH, Han KH: Early $\alpha$-fetoprotein response as a predictor for clinical outcome after localized concurrent chemoradiotherapy for advanced hepatocellular carcinoma. Liver Int 2011;31:369-376.

10 Spira D, Fenchel M, Lauer UM, Claussen CD, Gregor M, Bitzer M, Horger M: Comparison of different tumor response criteria in patients with hepatocellular carcinoma after systemic therapy with the multikinase inhibitor sorafenib. Acad Radiol 2011;18:89-96.

11 Bhide RS, Cai ZW, Zhang YZ, Qian L, Wei D, Barbosa S, Lombardo LJ, Borzilleri RM, Zheng X, Wu LI, Barrish JC, Kim SH, Leavitt K, Mathur A, Leith L, Chao S, Wautlet B, Mortillo S, Jeyaseelan R Sr, Kukral D, Hunt JT, Kamath A, Fura A, Vyas V, Marathe P, D’Arienzo C, Derbin G, Fargnoli J: Discovery and preclinical studies of (R)-1-(4-(4-fluoro-2-methyl-1H-indol-5-yloxy)-5- methylpyrrolo[2,1-f][1,2,4]triazin-6-yloxy)propan2-ol (BMS-540215), an in vivo active potent VEGFR-2 inhibitor. J Med Chem 2006;49:2143-2146.

-12 Ayers M, Fargnoli J, Lewin A, Wu Q, Platero JS: Discovery and validation of biomarkers that respond to treatment with brivanib alaninate, a small-molecule VEGFR-2/FGFR-1 antagonist. Cancer Res 2007;67:6899-6906.

13 Huynh H, Ngo VC, Fargnoli J, Ayers M, Soo KC, Koong HN, Thng CH, Ong HS, Chung A, Chow P, Pollock P, Byron S, Tran E: Brivanib alaninate, a dual inhibitor of vascular endothelial growth factor receptor and fibroblast growth factor receptor tyrosine kinases, induces grow th inhibition in mouse models of human hepatocellular carcinoma. Clin Cancer Res 2008;14:6146-6153.

14 Bhide RS, Lombardo LJ, Hunt JT, Cai ZW, Barrish JC, Galbraith S, Jeyaseelan R Sr, Mortillo S, Wautlet BS, Krishnan B, Kukral D, Malone H, Lewin AC, Henley BJ, Fargnoli J: The antiangiogenic activity in xenograft models of brivanib, a dual inhibitor of vascular endothelial growth factor receptor-2 and fibroblast growth factor receptor-1 kinases. Mol Cancer Ther 2010;9:369-378.

15 Park JW, Finn RS, Kim JS, Karwal M, Li RK, Ismail F, Thomas M, Harris R, Baudelet C, Walters I, Raoul JL: Phase II, open-label study of brivanib as first-line therapy in patients with advanced hepatocellular carcinoma. Clin Cancer Res 2011;17:1973-1983.

16 Finn RS, Kang YK, Mulcahy M, Polite BN, Lim HY, Walters I, Baudelet C, Manekas D, Park JW: Phase II, openlabel study of brivanib as second-line therapy in patients with advanced hepatocellular carcinoma. Clin Cancer Res 2012;18:2090-2098.

17 Johnson PJ, Qin S, Park JW, Poon RT, Raoul JL, Philip PA, Hsu CH, Hu TH, Heo J, Xu J, Lu L, Chao Y, Boucher E, Han KH, Paik SW, Robles-Aviña J, Kudo M, Yan L, Sobhonslidsuk A, Komov D, Decaens T, Tak WY, Jeng LB, Liu D, Ezzeddine R, Walters I, Cheng AL: Brivanib versus sorafenib as first-line therapy in patients with unresectable, advanced hepatocellular carcinoma: results from the randomized phase III BRISK-FL study. J Clin Oncol 2013;31:3517-3524.

18 Llovet JM, Decaens T, Raoul JL, Boucher E, Kudo M, Chang C, Kang YK, Assenat E, Lim HY, Boige V, Mathurin P, Fartoux L, Lin DY, Bruix J, Poon RT, Sherman M, Blanc JF, Finn RS, Tak WY, Chao Y, Ezzeddine R, Liu D, Walters I, Park JW: Brivanib in patients with advanced hepatocellular carcinoma who were intolerant to sorafenib or for whom sorafenib failed: results from the randomized phase III BRISK-PS study. J Clin Oncol 2013;31:3509-3516.

19 Giobbie-Hurder A, Gelber RD, Regan MM: Challenges of guarantee-time bias. J Clin Oncol 2013;31:29632969.

20 Edeline J, Boucher E, Rolland Y, Vauléon E, Pracht M, Perrin C, Le Roux C, Raoul JL: Comparison of tumor response by Response Evaluation Criteria in Solid Tumors (RECIST) and modified RECIST in patients treated with sorafenib for hepatocellular carcinoma. Cancer 2012;118:147-156.

-21 Bruix J, Reig M, Rimola J, Forner A, Burrel M, Vilana R, Ayuso C: Clinical decision making and research in hepatocellular carcinoma: pivotal role of imaging techniques. Hepatology 2011;54:2238-2244.

-22 Ho HK, Pok S, Streit S, Ruhe JE, Hart S, Lim KS, Loo HL, Aung MO, Lim SG, Ullrich A: Fibroblast growth factor receptor 4 regulates proliferation, anti-apoptosis and alpha-fetoprotein secretion during hepatocellular carcinoma progression and represents a potential target for therapeutic intervention. J Hepatol 2009;50:118-127.

-23 Lazarevich NL: Molecular mechanisms of alpha-fetoprotein gene expression. Biochem Mosc 2000;65:117133.

-24 Prajapati HJ, Spivey JR, Hanish SI, El-Rayes BF, Kauh JS, Chen Z, Kim HS: mRECIST and EASL responses at early time point by contrast-enhanced dynamic MRI predict survival in patients with unresectable hepatocellular carcinoma (HCC) treated by doxorubicin drug-eluting beads transarterial chemoembolization (DEB TACE). Ann Oncol 2013;24:965-973. 